\title{
Epididymal Lithiasis in Gallus gallus domesticus
}

- Author(s)
Rocha Jr. JM ${ }^{1}$
Mahecha GAB2
Dornas RAP2
Kuana SL3
Martins NRS ${ }^{3}$

1 Escola de Veterinária.
2 Instituto de Ciências Biológicas.
3 Perdigão Agroindustrial S.A.

\section{Mail Address}

NRS Martins

Universidade Federal de Minas Gerais

Av. Antônio Carlos, 6627

Campus Pampulha

31.270-010. Belo Horizonte, MG, Brazil.

E-mail: rodrigo@vet.ufmg.br

\section{ABSTRACT}

A study on the occurrence of epididymal lithiasis (EL) in Gallus gallus domesticus of different breeds and from different geographical regions of Brazil was carried out. Forty breeding roosters were collected in the states Santa Catarina, São Paulo, Minas Gerais, Espírito Santo and Goiás, representing two specific pathogen free Leghorn lines (SPF), one commercial Leghorn layer breeder (Hy-Line) line, two commercial broiler breeder lines (Ross and Cobb), and two backyard chicken flocks. In commercial poultry breeders, EL was observed mainly after 55 weeks of age, and lithus resulted in lower fertility caused by inadequate maturation of spermatozoa and testicular atrophy, which evolved to more severe testicular dysfunction at 100 weeks of age. One hundred percent of the sampled roosters of the evaluated SPF lines presented epididymal lithiasis, which was also observed in all commercial genetic lines. The analysis of EL occurrence revealed no differences among regions and breeds: all regions and genetic lines presented epididymal calculi and the occurrence seemed higher in the more intensively-reared chickens. As for the backyard roosters, 50\% presented calculi. Considering the occurrence of EL in the SPF flocks, its primary association with infectious bronchitis virus (IBV) infection was discarded, despite its contribution to fertility loss.

\section{INTRODUCTION}

The domestic chicken (Gallus gallus domesticus) is the most important domestic avian species for the industrial production of meat and eggs. In the Brazilian economy, these activities may reach $1.5 \%$ of the gross domestic product, and directly and indirectly generate 4.8 million jobs (Avicultura Brasileira, 2008). Under natural conditions, chickens present seasonal reproduction, and their sexual activity is dependent on the daylight stimulation of the pineal gland. In order to obtain maximum progeny output in intensive poultry reproduction, fertility must be continuous during the birds' adult life.

Epididymal lithiasis results in progressive precocious involution of the testes and reduced fertility in male breeders (Mahecha et al., 2002). In 1995, a rooster fertility pathology causing spermatic count reduction in the ejaculate was described in Cornish and White Rock chicken breeds, resulting in sperm retention and premature fertility decline. By 110 weeks of age, male fertility is reduced to $5 \%$, despite the natural potential of a 10-year-long fertility (Muncher et al., 1995). Janssen et al. (2000) reported in adult Leghorn roosters epididymal lithiasis, with calculi composed mainly of calcium (48\%), and reduced fertility, with the daily sperm production and testosterone levels that were significantly lower at 62 weeks of age as compared to normal roosters. In Brazil, Mahecha et al. (2002) described the occurrence of efferent ductule calculi $(43.5 \%$ 
calcium) in $94.3 \%$ of free-range or industrial roosters in Minas Gerais State, but not in other twenty-one different avian species of several Orders, and therefore, it was considered as disease of chickens. Boltz et al. (2004) studied Leghorn SPF chickens with EL, and demonstrated testicular mass reduction $(12.01 \pm 0.76 \mathrm{~g})$ as compared to normal birds $(15.2 \pm 0.81 \mathrm{~g})$, reduction of blood testosterone (lithiasis $3.6 \pm 0.3 \mathrm{ng} / \mathrm{ml}$ vs. normal $7.0 \pm 1.63 \mathrm{ng} / \mathrm{ml}$ ), and lower sperm number in $E L$ as compared to normal birds $\left(5.03 \pm 0.31 \times 10^{8}\right.$ sperm cells/testis/day vs. $7.43 \pm 0.52 \times 10^{8}$ sperm cells/testis/ day).

Considering that male breeders fertility loss has been a frequent complaint in industrial breeder production in the last few years, and that EL was previously detected in local free-range and commercial flocks (Mahecha et al., 2002), the objective of the present study was to evaluate the occurrence of $E L$ in male breeders of commercial chicken lines as compared to backyard chickens reared in regions distant from industrial chicken production regions.

\section{MATERIALS AND METHODS}

Both testes of at least 20 roosters from each flock of commercial Hy-Line egg-type breed, Ross and Cobb meat-type (broiler) breeds, two SPF flocks, and two backyard chicken flocks of three Brazilian regions (MidWest, Southeast, and South) were collected in 2007 (Table 1). All commercial roosters were obtained from culled flocks that were removed from reproduction, and that were older than 60 weeks of age. All backyard roosters were between two and three years of age.

Testes were analyzed in the Laboratory of Avian Diseases (Veterinary College, UFMG) and at the Reproduction Biology Laboratory (LABRE, ICB-UFMG). Calculi were counted per epididymis, and the condition was considered severe when 20 or more stones, occupying most of the tubular spaces, were counted. For histological and morphometric analyses, 5 testes from line and origin were collected. Each testis with epididymis was fixed in Bouin or 10\% formaldehyde PBS (phosphate buffered saline solution) for dispatch, and weighed (0.01 g precision, Sartorius BP 2105 scale) in the laboratory. Sections were placed in $70 \%$ alcohol wash, decalcified in Perenji solution, dehydrated in absolute ethanol, cleared in xylol, and embedded in paraffin. Thin sections $(0.7 \mu \mathrm{m})$ were stained with hematoxylin-eosin. Twelve tissue cross-sections were evaluated per testis.
Data were submitted to analysis of variance using GLM procedures, and means were compared by the test of Duncan (Sampaio, 1998).

\section{RESULTS AND DISCUSSION}

Calculi were found in the epididymis of all rooster genetic lines and regions of origin, but with different intensities and prevalence (Table 1). The occurrence of $E L$ in roosters of all regions and lines examined, including those from industrial and backyard flocks, suggests that the etiology and predisposing conditions of $E L$ pathogenesis are present in different environments, and it is possibly associated to a particular Gallus gallus domesticus susceptibility, as EL has not been detected yet in other avian species (Mahecha et al., 2002).

\begin{tabular}{|c|c|c|}
\hline Region of origin & Line & Prevalence \\
\hline Triângulo Mineiro - MG & Leghorn - SPF & $100 \%$ \\
\hline Grande Belo Horizonte - MG & Leghorn ${ }^{2}$ & $100 \%$ \\
\hline Zona da Mata - MG & Free-range $^{3}$ & $60 \%$ \\
\hline Castelo - ES & Free-range $^{3}$ & $40 \%$ \\
\hline Grande São Paulo - SP & Leghorn - SPF ${ }^{1}$ & $80 \%$ \\
\hline Noroeste de São Paulo - SP & Hy-Line ${ }^{2}$ & $100 \%$ \\
\hline Oeste de Santa Catarina - SC & $\mathrm{Cobb}^{4}$ & $100 \%$ \\
\hline Sul de Goiás - GO & Ross $^{4}$ & $100 \%$ \\
\hline \multicolumn{3}{|c|}{$\begin{array}{l}\text { Notes: } 1 \text { - Leghorn SPF were confined in controlled environment chickens; } \\
2 \text { - Leghorn industrial egg-type breeder; } 3 \text { - Isolated unselected free- } \\
\text { range flocks; } 4 \text { - Industrial meat-type (heavy) breeder. }\end{array}$} \\
\hline
\end{tabular}

The number of stones per epididymis was higher in industrial roosters as compared to backyard birds. Severe cases of calculi formation were frequent in industrial and SPF breeds, and amounted to 20 stones or more per epididymis.

Stones were irregular in shape and light (whitish) in color (Figure 1), varying from fine granules up to $3 \mathrm{~mm}$ in length, which is consistent with an earlier detailed description of epididymal stones (Mahecha et al., 2002). The microscopical examination of the efferent ductules revealed lithiasis within the ductule, which was dilated and presented epithelial folding loss, vacuolization, sloughing, and mononuclear infiltration (Figure 2).

There may be an association between intensive rearing and EL severity, as the more intensively reared and confined roosters presented had higher EL severity, with $100 \%$ prevalence in industrial breeds, including SPF, as compared to the lower incidence (40-60\%) in backyard roosters. Considering that the free-range roosters examined derived from isolated flocks that 


\section{Rocha Jr. JM, Mahecha GAB, Dornas RAP, Kuana SL, Martins NRS}

Epididymal Lithiasis in Gallus gallus domesticus were reared distant from industrial production areas and did not employ industrial chickens inputs, such as vaccines and balanced feeds, it is possible that there may be a natural environmental cause for EL, which was present in at least two different geographical regions -one backyard flock was reared in Minas Gerais and the other, in Espirito Santo.

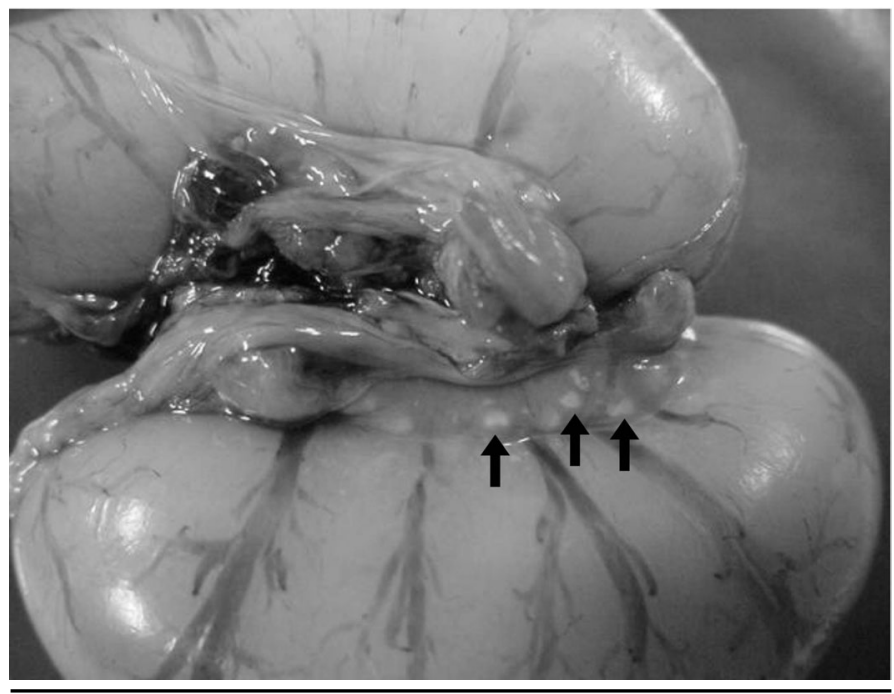

Figure 1 - Testes and epididymis of a 108-week-old industrial rooster. Abundant calculi are present in various sizes and with irregular shapes in the epididymis (arrows).

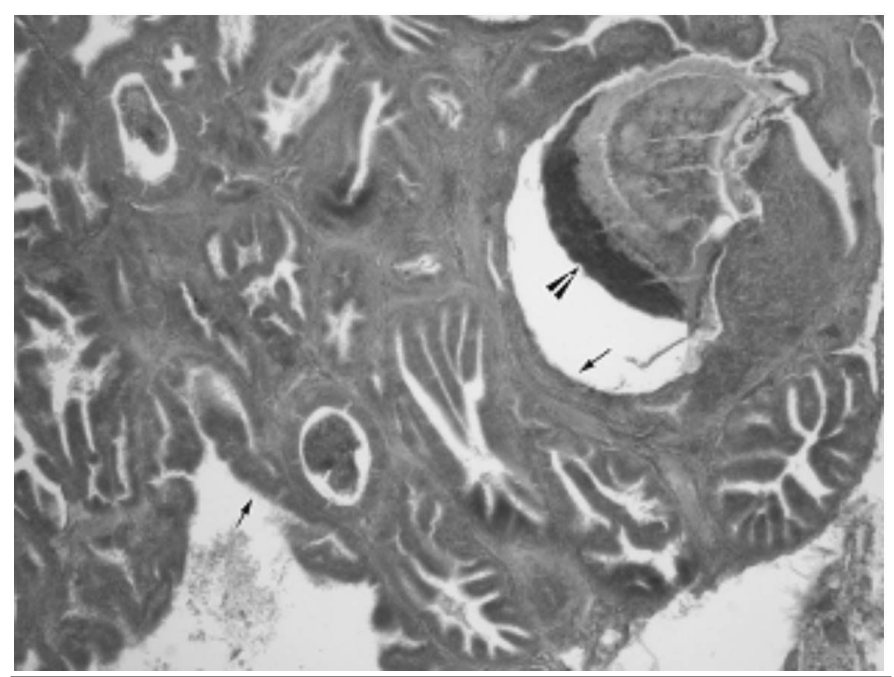

Figure 2 - Microphotograph of the efferent ductule of a 35week-old industrial rooster. The efferent ductule is dilated, with epithelial folding loss (arrows) and with calculus (arrow head) in its interior (100x - HE).

The prevalence of EL was determined for different rooster lines and regions of origin. The two evaluated specific pathogen free (SPF) chicken lines, both certified controlled-environment origin flocks, presented high prevalence of EL, that is, both presented lithiasis in the epididymis. One SPF flock, reared in Minas Gerais state, had $100 \%$ prevalence and the other, from São Paulo state, presented $80 \%$ prevalence. The presence of $\mathrm{EL}$ in SPF flocks is a relevant finding when investigating EL etiology. For instance, the previous suggestion that EL was caused by a disease primarily caused by IBV must be discarded, at least when the IBV strains employed for monitoring the SPF flocks are considered, as opposed to the findings of Boltz et al. (2004). However, it is recognized and emphasized that IBV may exert a significant role in the pathogenesis and aggravation of epididymal lithiasis in the field. It is also relevant to take into account that SPF flocks are regularly monitored for antibodies and antigens of several other viruses and bacteria, in addition to IBV.

Janssen et al. (2000) observed that epididymal lithiasis may cause chronic inflammation, with abundant mononuclear, mainly lymphocytic, infiltrates and epithelial sloughing, which may evolve to the complete destruction of the epidydimal epithelium. Those authors considered as possible EL causes IBV or the elevated dietary concentration of calcium or vitamin D3. In contrast, however, a high prevalence $(80-100 \%)$ of severe EL was found in roosters from two independent commercial SPF flocks in the present study, both maintained in environmentally-controlled houses and regularly monitored for IBV.

No difference was found in EL incidence between commercial meat-type and egg-type breeds of chickens, all of which showed high EL prevalence $(100 \%)$, irrespective of origin; however, backyard roosters, presented lower prevalence, of $40-60 \%$.

The theoretical economic impact of $E L$ is worth considering. Intensive breeding requires a ratio of one male per every ten females. Depending on male fertility, each hen is capable of laying an average of 180 eggs per cycle of about 52 weeks, and each rooster may potentially fertilize 1,800 eggs during the period of reproductive activity. Considering that in Brazil, in 2007, approximately 39 million broiler and layer breeders were in activity, a 1\% loss in fertility - a relatively conservative reduction - may represent (one percent of 39 million times 1,800 ) a reduction of approximately 7 million chicks. In addition, a longer fertility lifespan will increase the output, reduce the need of replacement males as well as the cost of raising a new flock of breeders (Renden \& Pierson, 1982).

\section{CONCLUSION}

The present study showed that EL is highly prevalent in the main chicken genetic lines and Brazilian poultry 
production regions. The most surprising finding was the presence of EL in SPF flocks, considering that the etiology of $E L$ is unknown and may be of infectious origin, although not primarily due to IBV. The pathogenesis of EL is possibly multifactorial, and may be exacerbated by interacting factors present in the poultry industrial production, such as infections by IBV and other pathogens, as well as nutritional factors. As to IBV, it has come to our knowledge that, in regions with multiple-age flocks receiving multiple live IBV vaccinations, the severity of EL was higher.

\section{REFERENCES}

Avicultura Brasileira. Audiência Pública da Comissão de Agricultura, Pecuária, Abastecimento e Desenvolvimento Rural [citado $2009 \mathrm{fev}$ 10]. Disponível em: http://www2.camara.gov.br/comissoes/capadr/ audiencias-2008/rap270508tomelin.ppt

Boltz DA. et al. Avian infectious bronchitis virus: a possible cause of reduced fertility in the rooster. Avian Diseases 2004; 48:909-915.

Janssen SJ. et al. Identification of the epididymal stones in diverse rooster populations. Poultry Science 2000; 79:568-574.

Mahecha GAB. et al. Epididymal lithiasis in roosters and efferent ductule and testicular damage. Reproduction 2002; 124: 821-834.

Muncher $Y$. et al. Intratesticular retention of sperm and premature decline in fertility in the domestic rooster, Gallus domesticus. Journal of Experimental Zoology 1995; 273: 76-81.

Renden JA, Pierson ML. Long term reproductive performance of broiler breeder males selected for semen production. Poultry Science 1982; 61(6):1214-1217.

Sampaio IBM. Estatística aplicada à experimentação animal. Belo Horizonte: Fundação de Ensino e Pesquisa em Medicina Veterinária e Zootecnia; 1998. 221 p. 